\title{
RANCANG BANGUN PURWARUPA TEKNOLOGI MIKROHIDRO MENGGUNAKAN KONSEP HIDRO FLUTTER
}

\author{
I P G Sopan Rahtika, I Made Suarta, dan Putu Wijaya Sunu \\ Jurusan Teknik Mesin Politeknik Negeri Bali \\ Bukit Jimbaran, P.O. BOX 1064 Tuban, Badung, BALI \\ Phone:+62-361-701981, Fax:+62-361-701128 \\ E-mail: sopan_rahtika@yahoo.com
}

\begin{abstract}
Abstrak
Menurunnya cadangan minyak dunia menjadi krisis global untuk beberapa dasawarsa ke depan. Pencarian alternatif energi terbaharui menjadi topik urgen tren penelitian saat ini. Indonesia memiliki keberlimpahan ketersediaan energi berupa potensi pengembangan mikrohidro. Penelitian ini merupakan penelitian pengembangan teknologi inovatif baru dalam teknologi mikrohidro berupa teknik pengkonversian energi aliran air menjadi energi listrik menggunakan teknologi hidro flutter. Dalam penelitian ini dilakukan pengembangan alat baru pengkonversian energi dari aliran air menjadi energi listrik. Sebuah purwarupa dibangun yang bisa pengekstrak energi dari aliran air di kali menjadi energi mekanik yang siap di konversi menjadi energi listrik menggunakan prinsip hydro flutter dari sebuah flexibly mounted free leading edge cantilevered rigid plate. Keunggulan dari konsep baru yang ditawarkan adalah kesederhanaan dari desain dan kemampuan untuk membersihkan sistem sendiri sehingga mengurangi biaya pemeliharaan.
\end{abstract}

Kata Kunci: mikrohidro, hydro flutter, free leading edge cantilevered rigid plate

\begin{abstract}
The decline of the world oil reserves is a global crisis for decades to come. The search for renewable energy alternatives is an urgent topic of current research trends. Indonesia has an abundance of energy availability in the form of potential microhydro development. This research is a research of development of new innovative technology in microhydro technology in the form of conversion technique of water flow energy into electric energy using hydro flutter technology. In this research, the development of new tool to convert energy from water flow into electrical energy was developed. A prototype was built that can extract energy from the water stream at times into mechanical energy ready for conversion into electrical energy using the hydro flutter principle of a flexibly mounted free leading edge cantilevered rigid plate. The advantages of the new concept are the simplicity of the design and the ability to clean the system by itself, thereby reducing the maintenance costs.
\end{abstract}

Keywords: microhydro, hydro flutter, free leading edge cantilevered rigid plate

\section{PENDAHULUAN}

Penggunaan minyak bumi sebagai sumber energi terus meningkat yang mengakibatkan semakin menurunnya cadangan minyak dunia. Penurunan ini merupakan krisis global untuk beberapa dasawarsa ke depan. Selain itu, penggunaan bahan bakar fosil juga menjadi pemicu krisis lingkungan dalam bentuk polusi dan pemanasan global. Pencarian alternatif energi terbaharui dan ramah lingkungan menjadi topik urgen tren penelitian saat ini.
Review tentang status perkembangan mikrohidro di Indonesia diteliti oleh Erinofiardi et. al. (2017) menunjukkan tingginya potensi mikrohidro di Indonesia karena tingginya curah hujan dan banyaknya sungai dan saluran air yang lebih kecil. Pengembangan mikrohidro melalui design Agnew turbin dilakukan oleh Mirzaei et. al. (2015). Axialflow turbin diteliti oleh Alexander et. al. (2009) untuk aplikasi head yang rendah. Penelitian secara sosio-ekonomi terhadap potensi mikrohidro dilakukan oleh Purwato dan Afifah (2016).Potensi 
pengembangan mikrohidro di Tanzania dilakukan oleh Adebayo et. al. (2013).

Pemahaman secara ilmiah tentang fenomena flutter bisa dicari jejaknya mulai dari NACA Technical Report No. 496 tentang General Theory of Aerodynamic Instability and the Mechanism of Flutter (Theodorsen, 1934). Dalam laporan ini, Theodorsen menjelas secara theori bagaimana flutter bisa terjadi pada sayap pesawat terbang dengan menjelaskan interaksi antara elastisitas dari struktur, gaya inersia, dan gaya aerodinamik. Dinamika sayap pesawat di model kedalam bentuk matematis dan solusi dari model itu bisa menjelaskan timbulnya flutter. Penelitian ini dilanjutkan menjadi investigasi eksperimental dan dilaporkan dalam NACA Technical Report No. 685 (Theodorsen, 1940). Efek penambahan Aeleron dan Tab terhadap flutter selanjutnya dilaporkan dalam NACA Technical Report No.736 (Theodorsen, 1941).

Fenomena Flutter juga ditemui dalam dunia engineering diluar pesawat udara. Runtuhnya jembatan Tacoma Narrows Bridge di negara bagian Washinton Amerika Serikat pada tahun 1940 akhirnya disimpulkan sebagai kegagalan dalam desain akibat mengabaikan efek aerodinamik. Jembatan mengalami flutter saat hembusan angin dengan kecepatan 48 km/jam datang (Fox,1994).

Dengan hadirnya teknologi komputer, analysis tentang flutter banyak yang memakai finite element method. Peneliti LAPAN melakukan Flutter Analysis untuk mengoptimalkan desain Fin dari roket peluncur satelit (Andria, 2010). Manikandan melakukan metode finite elemen untuk mengoptimisi sistem mounting dari aerofoil flutter test (Manikandan, 2011).

Beberapa penelitian terbaru tentang thin flat plate diantaranya dilakukan oleh Gibbs (2012), Tang (2009), Zhao (2012), Howell (2009), dan Howell (2011). Gibbs (2012) melakukan secara eksperimen dan theory terhadap flutter dari flat plate dengan fixed leading edge memakai tiga dimensi analisis terhadap axial flow. Tulisannya membahas tentang flutter characteristic sebagai fungsi dari mass ratio dan aspect ratio (Gibbs,2012).

Liosha Tang (2009) membahas flutter dari dua buah flat plate yang diposisikan secara paralel dengan aliran fluida ke arah axial. Dinamika dari sistem dibangun menghasilkan nonlinear model. Penekanan pada tulisan Tang (2009) lebih banyak pada kerangka theori dan belum mencapai eksperimen.

Zhao (2012) secara lengkap baik theori maupun eksperimen membahas flutter dari flat plate.
Pembahasan lebih menekankan nonlinear analisis seperti pembuatan poincare maps. Hasil nonlinear analisis ditunjukkan dengan eksperimen.

Howell (2009) memakai fluid-flow interaction untuk membahas sifat dari cantilevered plate dengan ideal flow. Kerja dilanjutkan dengan membahas effect dari inertial homogeneity terhadap flutter.

Berangkat dari latar belakang ini, peneliti bermaksud untuk mengembangkan teknologi baru sebagai bentuk bentuk jawaban atas krisis ini. Indonesia memiliki keberlimpahan ketersediaan energi berupa potensi pengembangan mikrohidro. Penelitian ini merupakan penelitian pengembangan teknologi inovatif baru dalam teknologi mikrohidro berupa teknik pengkonversian energi aliran air menjadi energi listrik menggunakan teknologi hidro flutter. Dalam penelitian ini akan dilakukan pengembangan alat baru pengkonversian energi dari aliran air menjadi energi listrik.

Sebuah purwarupa akan dibangun yang bisa pengekstrak energi dari aliran air di kali menjadi energi mekanik yang siap di konversi menjadi energi listrik menggunakan prinsip hydro flutter dari sebuah flexibly mounted free leading edge cantilevered rigid plate. Selama ini telah tersedia berbagai teknik pengkonversian energy mikrohidro menjadi energi listrik seperti kincir air, turbin ulir, axial turbin. Keunggulan dari konsep baru yang ditawarkan adalah kesederhanaan dari desain, minimum biaya konstruksi sipil dan kemampuan untuk membersihkan system sendiri sehingga mengurangi biaya pemeliharaan.

Teknologi mikrohidro yang dikembangkan dalam penelitian ini menggunakan sebuah rigid plate yang terpasang secara fleksibel dengan sebuah pegas pada sebuah tiang. Ujung plat yang bebas diarahkan menghadap ke aliran air. Plat akan mengalami flutter apabila kombinasi kekakuan pegas, inertia sistem, dan kecepatan aliran air yang sesuai. Fenomena flutter inilah yang akan dipakai sebagai pengekstrak energy aliran fluida menjadi energy mekanis plat. Energi mekanik plat ini akan diteruskan ke sebuah alternator yang akan digunakan untuk pengkonversi ke energi listrik.

Penelitian ini merupakan penelitian awal dimana sebuah purwarupa akan dibangun untuk membangun sebuah alat yang bisa mengektrak energy aliran fluida cair. Sebuah fungsional test akan dilakukan bahwa purwarupa bisa berfungsi dengan baik. Pengkonversian energy listrik bukan merupakan scope penelitian tahap ini dan akan menjadi penelitian tahap berikutnya. 
Penelitian ini termasuk jenis penelitian rancang bangun. Bersamaan dengan ini, ditetapkan rumusan masalah yang menjadi batasan penelitian ini adalah sebagai berikut:

a. Bagaimana konfigurasi purwarupa dari teknologi mikrohidro yang menggunakan prinsip hydro flutter dari sebuah flexibly mounted free leading edge cantilevered rigid plate, berikut cara kerja dan komponen-komponennya?

b. Berapa ukuran optimal masing-masing komponen dari alat tersebut sehingga dapat berfungsi bersama mengekstrak energy dari aliran fluida secara efisien?

Tujuan penelitian ini adalah untuk merancang bangun sebuah purwarupa sebuah teknologi mikrohidro yang menggunakan prinsip hydro flutter dari sebuah flexibly mounted free leading edge cantilevered rigid plate sebagai sebuah desain yang mudah dimanufaktur dan berkinerja optimum. Secara lebih spesifik, tujuan khusus penelitian ini bisa dinyatakan sebagai berikut:

a. Untuk menentukan konfigurasi, komponen dan cara kerja purwarupa sebuah teknologi mikrohidro yang menggunakan prinsip hydro flutter dari sebuah flexibly mounted free leading edge cantilevered rigid plate sebagai sebuah desain yang mudah dimanufaktur dan berkinerja optimum.

b. Melakukan penghitungan untuk menentukan ukuran optimal dari masing-masing komponen sehingga dapat berfungsi sebagai pengekstrak energy dari aliran fluida cair.

c. Membangun dan melakukan fungsional test terhadap purwarupa yang telah dibangun.

\section{METODE PENELITIAN}

Penelitian pengembangan merupakan salah satu bentuk dari penelitian rancang bangun yang tidak lain adalah sebuah iteratif proses. Tahap awal penelitiaan ditetapkan tujuan rancang bangun yaitu membangun sebuah purwarupa teknologi mikrohidro. Selanjutnya dalam iteratif proses dilakukan penentuan cara kerja alat, dilanjutkan dengan penentuan parameter desain berupa ukuran masing-masing komponen, dilanjutkan pembuatan gambar teknik, pembuatan komponen, perakitan alat, dan diakhiri dengan pengujian alat. Dalam penelitian ini dilakukan pengujian fungsional, yaitu menentukan alat bisa berfungsi apa tidak. Perbaikan design dilaksanakan melalui proses iteratif dengan perubahan cara kerja, ukuran komponen, yang dilanjutkan dengan pembuatan ulang komponen dan perakitan.

\section{HASIL DAN PEMBAHASAN}

Hasil penelitian ini berupa design purwarupa teknologi mikro hidro seperti pada gambar 1. Dengan kombinasi ukuran kekakuan pegas mounting, inersia system, dan kecepatan aliran fluida maka rigid plate akan mengalami flutter bergerak bolak-balik. Pegas stopper berfungsi untuk membatasi maksimum defleksi dari rigid plate. Gerakan bolak-balik dari rigid plate diubah menjadi gerakan putaran oleh poros engkol. Gerakan putaran ini siap dikonversi menjadi energy listrik.

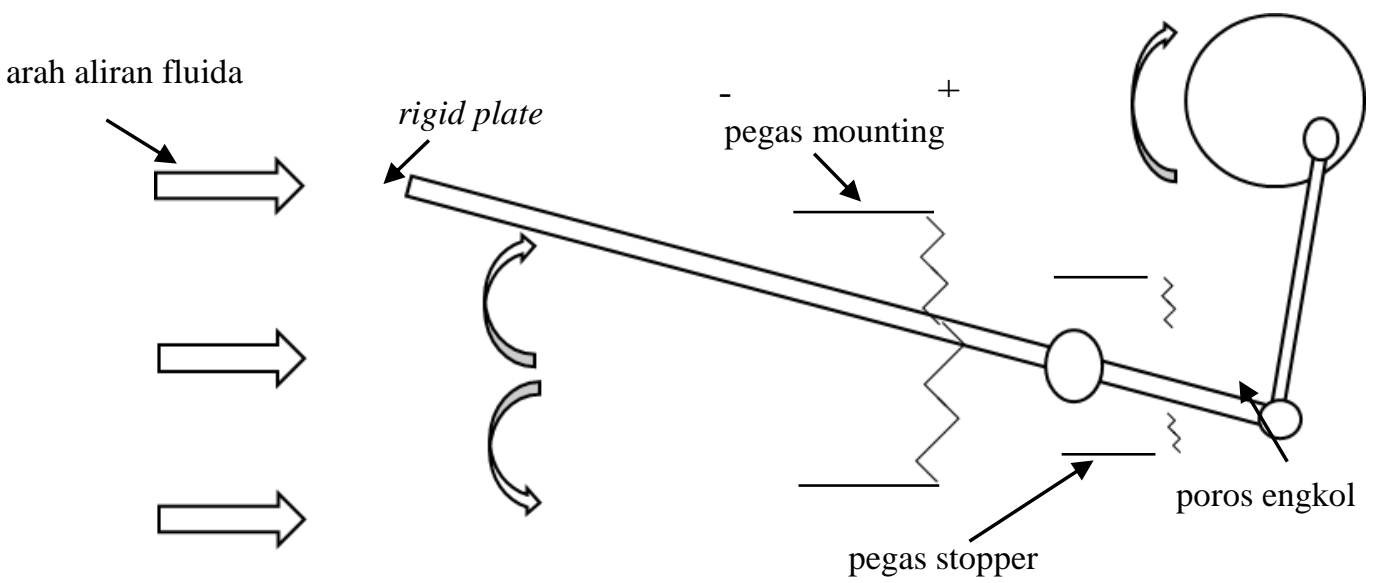

Gambar 1. Rancangan teknologi mikrohidro menggunakan konsep hydro flutter dari flexibly mounted rigid plate 
Sebagai penelitian awal penelitian ini focus pada dinamika mekanis dari rigid plate dan mekanis flutter sehingga alat yang didesain akan berfungsi dalam mengekstrak energy dari aliran fluida. Pengkonvesian energy listrik akan dilakukan pada penelitian lanjutan.

Pengkonversian energi fluida menjadi energi mekanik dilakukan oleh rigid plate. Hydro flutter adalah salah satu fenomena dinamik hidroelastisitas dimana gaya-gaya hidrodinamik bekerja bersama dengan natural mode getaran dari sebuah struktur menghasilkan gerak periodik. Gaya aerodinamik berfungsi menjadi energi input ke getaran struktur yang bila tidak teredam oleh sistem damping maka amplitude getaran akan bertambah besar. Hydro flutter adalah kondisi tidak stabil (unstable condition) sehingga sering diistilahkan sebagai kondisi kritikal. Kondisi kritikal berhubungan dengan satu kecepatan aliran fluida yang disebut flutter speed. Sebelum mencapai kecepatan ini, flat-plate akan bergetar mengalami Limit Cycle Oscillation (LCO). Kondisi kecepatan dibawah kondisi kritikal disebut kondisi sub-kritikal (sub-critical condition). Pada kondisi ini, sistem damping mampu meredam getaran dan menghindari sistem dari kegagalan struktur. Alat yang dikembangkan pada penelitian ini memanfaatkan fluttering rigid-plate pada kondisi sub-kritikal, sehingga aman dari kerusakan.

Selanjutnya energi mekanik dari rigid-plate akan diubah menjadi energi listrik yang akan diteliti pada peneitian selanjutya.

\section{SIMPULAN}

Sebuah inovasi novel telah dirancang dalam teknologi mikrohidro dalam penelitian ini. Inovasi baru berupa rancangan purwarupa teknologi mikro hidro dengan flexibly mounted rigid plate dengan free leading edge.

\section{DAFTAR PUSTAKA}

[1] Adebayo, Eric; Sovacool, Benjamin K.; \& Imperiale, Sara. (2013) It's about dam time: Improving microhydro electrification in Tanzania. Energy for Sustainable Development. 17 (2013) 378-385

[2] Alexander; K.V.; Giddens, E.P.; \& Fuller, A.M.(2009) Axial-flow turbines for low head microhydro systems. Renewable Energy 34 (2009) 35-47

[3] Andria, Novi \& Triharjanto Robertus Heru (2010) Optimal Design of RX-420 Fin Using Flutter Analysis. The ITB Regional Conference on Mechanical and Aerospace Engineering. 1719 Februari 2010, Denpasar, Bali

[4] Erinofiardia; Gokhalec, Pritesh; Datea, Abhijit; Akbarzadeha, Aliakbar; Bismantolob, Putra; Suryono, Ahmad Fauzan; Mainil, Afdhal Kurniawan; \& Nuramal, Agus (2017) A review on micro hydropower in Indonesia, Energy Procedia. 110(2017) 316-321

[5] Fox, Robert W. \& McDonald, Alan. T. (1994). Introduction to Fluid Mechanics. John Wiley \& Son, Inc.

[6] Gibbs, S. Chad, Wang, Ivan, and Dowell, Earl. (2012) Theory and experiment of a rectangular plate with fixed leading edge in threedimensional axial flow, Journal of Fluids and Structures. 34(2012) 68-83

[7] Howell, R.M., Lucey, A.D., Carpenter, P.W., Pitman, M.W. (2009) Interaction between a cantilevered-free flexible plate and ideal flow. Journal of Fluids and Structures.25 (2009) 544566

[8] Howell, R.M., Lucey, A.D., Pitman, M.W. (2011) The effect of inertial in homogeneity on the flutter of a cantilevered flexible plate. Journal of Fluids and Structures 27 (2011) 383-393

[9] Manikandan,G. \& Rao, M. Ananda (2011) Aerofoil Flutter Analysis, Simulation and Optimization. International Journal of Advance Engineering Sciences and Technologies, 4 (1), 053-068.

[10]Mirzaei, Ammar; Shojaeefard, Mohammad Hassan; Babaei, Ali; \& Yassi, Yousef. (2015) Experimental study of redesigned draft tube of an Agnew microhydro turbine. Energy Conversion and Management. 105(2015) 488487

[11] Purwanto, Widodo Wahyu; \& Afifah, Nok. (2016) Assessing the impact of techno socioeconomic factors on sustainability indicators of microhydro power projects in Indonesia: Acomparative study. Renewable Energy. 93 (2015) 312-322

[12] Rahtika, I.P.G. Sopan; Wardana, I.N.G.; Sonief, A.A.; \& Siswanto, E. (2017a) Experimental Investigation on Flutter Similitude of Thin-Flat Plates. Advances in Acoustics and Vibration.

[13] Rahtika, I.P.G. Sopan; Wardana, I.N.G.; Sonief, A.A.; \& Siswanto, E. (2017b) Numerical and experimental investigation on the flutter of cantilevered plates with free leading edge in axial flow. Journal of Engineering Science and Technology. Vol. 12, No. 10 (2017) 2805 - 2825 
[14] Tang, Liaosha, and Paı"doussis, Michael P. (2009) The coupled dynamics of two cantilevered flexible plates in axial flow. Journal of Sound and Vibration. 323 (2009) 790-801

[15] Theodorsen, Theodore (1934) General Theory of Aerodynamic Instability and the Mechanism of Flutter, NACA Technical Report No. 496.

[16] Theodorsen, Theodore \& Garrick, L.E. (1940) Mechanism of Flutter: A Theoritical and
Experimental Investigation of the Flutter Problem, NACA Technical Report No. 685.

[17]Theodorsen, Theodore \& Garrick, L.E. (1941) Nonstationary Flow abaout A Wing-Aeleron-Tab Combination Including Aerodynamic Balance, NACA Technical Report No. 736 